\title{
Evaluation of Long-term Outcomes of Correction of Severe Blepharoptosis with Advancement of External Levator Muscle Complex: Descriptive Statistical Analysis of the Results
}

\author{
ALESSANDRO INNOCENTI ${ }^{1}$, FRANCESCO MORI ${ }^{1}$, DARIO MELITA $^{1}$, \\ EMANUELA DREASSI ${ }^{2}$, FRANCESCO CIANCIO $^{3}$ and MARCO INNOCENTI $^{1}$ \\ ${ }^{1}$ Plastic and Reconstructive Microsurgery, Careggi Universital Hospital, Florence, Italy; \\ ${ }^{2}$ Department of Statistics, Informatics, Applications "G.Parenti" DiSIA, University of Florence, Florence, Italy; \\ ${ }^{3}$ Department of Plastic and Reconstructive Surgery, University of Bari, Foggia, Italy
}

\begin{abstract}
Aim: Evaluation of long-term results after aponeurotic blepharoptosis correction with external levator muscle complex advancement. Patients and Methods: We carried out a retrospective study with medical record review of 20 patients (40 eyes) affected by bilateral aponeurotic moderate and severe ptosis who underwent primary surgery between January 2010 and December 2013. Criteria for outcome evaluations included 3-year postoperative follow-up of upper margin reflex index (uMRD) and symmetry. Results: 3-Year postoperative follow-up showed 17 (85\%) cases of successful correction of ptosis and three cases (15\%) showed partial success. Two eyes showed hypocorrection, while one eye was overcorrected. The symmetry was maintained in all patients except for the oldest. Conclusion: External superior levator advancement is an effective procedure for moderate and severe aponeurotic blepharoptosis correction, and establishes good long-term eyelid position and symmetry.
\end{abstract}

Normally the lower border of the upper eyelid lies $1.5 \mathrm{~mm}$ below the superior corneal limbus (1). Blepharoptosis is defined as an abnormally low position of the upper eyelid margin that may cause visual defects (2). It may require surgical correction both for functional and esthetical appearance. This condition may be mono- or bilateral and can be part of syndromes (3). Blepharoptosis can be classified according to various criteria such as: age of onset (congenital or acquired), etiology

This article is freely accessible online.

Correspondence to: Alessandro Innocenti, Viale Giacomo Matteotti 42, 50132 - Firenze, Italy. Mobile: +39 3356556335, e-mail innocentialessandro@alice.it

Key Words: Ptosis, blepharoptosis, ptosis surgery outcome, eyelid surgery, eyelid ptosis correction. (myogenic, neurogenic, aponeurotic, mechanical or traumatic) (4), levator functional excursion and severity. Based on severity, it may be minimal when the distance from the central corneal light reflection to the upper lid margin (upper margin reflex index:UMRD) is $\geq 2 \mathrm{~mm}$, moderate $\geq 1 \mathrm{~mm}$ or severe $<1 \mathrm{~mm}$ (5). Levator functional excursion is determined by measuring the excursion of the upper eyelid margin as the patient looks from down to up, while the eyebrow is manually fixed against the supraorbital rim.It is classified as poor (0-4 mm), moderate (5$10 \mathrm{~mm}$ ) or good (>10 mm) (6). Aponeurotic ptosis is the most common type of acquired ptosis. It results from involutional changes of the levator aponeurosis due to its gradual stretching or attenuation (Figure 1). Loss of aponeurotic tightness results in a narrow vertical dimension of the palpebral fissure, higher upper eyelid crease and deeper superior sulcus, while levator function usually remains normal. Chronic contact lens use, prior ocular surgery, cataract surgery and traumas are the most common causes of acquired aponeurotic ptosis (7). In this article, we report a retrospective study, conducted between January 2010 and December 2013, with the aim of evaluating long-term outcomes of correction of primary severe aponeurotic ptosis using external levator advancement performed alone or with concurrent blepharoplasty.

\section{Patients and Methods}

A retrospective review of medical records of 20 patients (40 eyes), affected by bilateral aponeurotic ptosis who underwent primary surgery between January 2010 and December 2013 was conducted. Demographic information including age, gender, medical history, surgical information and pre- and postoperative digital photographs were collected.

All the patients were examined in sitting position, with primary gaze, and grade of ptosis was evaluated in millimeters. Levator muscle function was determined by measuring the excursion of the eyelid margin as the patient looked from down to up. In order to prevent the frontalis muscle contribution, the eyebrow was manually fixed against the supraorbital rim. All the procedures were 
in vivo $31: 111-116(2017)$

Table I. Demographic data, and preoperative and postoperative measurements.

\begin{tabular}{|c|c|c|c|c|c|c|c|c|c|c|}
\hline $\begin{array}{l}\text { Case } \\
\text { no. }\end{array}$ & Age, & $\begin{array}{l}\text { Gender } \\
\text { years }\end{array}$ & $\begin{array}{c}\text { Grade of } \\
\text { ptosis }\end{array}$ & $\begin{array}{c}\text { uMRD } \\
\text { RE (mm) }\end{array}$ & $\begin{array}{c}\text { uMRD } \\
\text { LE (mm) }\end{array}$ & $\begin{array}{l}\text { Interlid uMRD } \\
\text { difference } \\
(\mathrm{mm})\end{array}$ & $\begin{array}{l}\text { Interlid crease } \\
\text { difference } \\
(\mathrm{mm})\end{array}$ & $\begin{array}{l}\text { Interlid show } \\
\text { difference } \\
(\mathrm{mm})\end{array}$ & Outcome & $\begin{array}{c}\text { Blepharo- } \\
\text { plasty }\end{array}$ \\
\hline 1 & 67 & $\mathrm{M}$ & RE severe/LE severe & 3.25 & 2.62 & 0.63 & 0.08 & 0.74 & Partial success & No \\
\hline 2 & 58 & $\mathrm{~F}$ & RE severe/LE severe & 4.36 & 4.70 & 0.34 & 0.42 & 0.23 & Success & No \\
\hline 3 & 72 & M & RE severe/LE severe & 4.26 & 3.69 & 0.57 & 0.43 & 0.05 & Success & Yes \\
\hline 4 & 77 & $\mathrm{~F}$ & RE severe/LE severe & 3.12 & 3.46 & 0.34 & 0.47 & 0.37 & Success & Yes \\
\hline 5 & 76 & $\mathrm{~F}$ & RE moderate/LE severe & 4.01 & 3.82 & 0.19 & 0.74 & 0.30 & Success & No \\
\hline 6 & 56 & $\mathrm{~F}$ & RE moderate/LE severe & 4.62 & 4.87 & 0.25 & 0.09 & 0.21 & Success & Yes \\
\hline 7 & 77 & $\mathrm{~F}$ & RE moderate/LE severe & 4.80 & 5.13 & 0.33 & 0.60 & 0.49 & Partial success & No \\
\hline 8 & 78 & $\mathrm{~F}$ & RE severe/LE severe & 2.06 & 3.96 & 1.90 & 2.33 & 0.35 & Partial success & No \\
\hline 9 & 33 & $\mathrm{~F}$ & RE severe/LE severe & 4.09 & 4.27 & 0.18 & 0.14 & 0.26 & Success & No \\
\hline 10 & 45 & M & $\mathrm{RE}$ moderate/LE severe & 4.19 & 4.66 & 0.47 & 0.43 & 1.30 & Success & No \\
\hline 11 & 61 & M & RE severe/LE severe & 4.58 & 4.22 & 0.36 & 0.28 & 0.72 & Success & No \\
\hline 12 & 62 & M & RE moderate/LE severe & 4.56 & 4.26 & 0.30 & 0.23 & 0.63 & Success & No \\
\hline 13 & 56 & M & RE severe/LE moderate & 4.19 & 4.56 & 0.37 & 0.36 & 0.41 & Success & No \\
\hline 14 & 55 & $\mathrm{~F}$ & RE severe/LE severe & 4.41 & 4.04 & 0.37 & 0.47 & 0.35 & Success & Yes \\
\hline 15 & 77 & $\mathrm{~F}$ & RE moderate/LE moderate & 4.41 & 4.24 & 0.17 & 0.22 & 0.33 & Success & No \\
\hline 16 & 73 & $\mathrm{~F}$ & RE moderate/LE moderate & 4.05 & 4.60 & 0.55 & 0.82 & 0.41 & Success & Yes \\
\hline 17 & 71 & $\mathrm{~F}$ & RE severe/LE severe & 4.42 & 4.60 & 0.18 & 0.60 & 0.28 & Success & Yes \\
\hline 18 & 65 & M & RE severe/LE moderate & 4.18 & 3.67 & 0.51 & 0.60 & 0.29 & Success & No \\
\hline 19 & 37 & $\mathrm{~F}$ & RE moderate/LE severe & 3.69 & 4.14 & 0.45 & 0.78 & 0.97 & Success & No \\
\hline 20 & 56 & M & RE severe/LE severe & 4.13 & 3.76 & 0.37 & 0.48 & 0.19 & Success & No \\
\hline
\end{tabular}

uMRD: upper margin reflex index; RE: right eye; LE:left eye; M: male; F: female.

performed under local anesthesia by the same author (AI). Three different clinicians collected the pre-and postoperative measurements with a caliper; the pre-and postoperative average data were then compared and analyzed. The study complies with the policies of the local Institutional Review Board. All patients signed a specific form for consent to the use of photos and personal data.

Inclusion criteria: age $>18$ years, eyelid severe/moderate ptosis with presence of levator muscle function. Exclusion criteria included: previous eyelid or eyebrow surgical procedures, absence of levator muscle function and non-aponeurotic ptosis. Preoperative measurements included: the grade of ptosis basing on upper margin reflex distance (uMRD) and assessment of levator function.

Postoperative measurements included: UMRD, interlid uMRD difference, interlid crease difference and interlid show difference (Figure 2). The interlid uMRD difference represents the difference between the postoperative uMRD between the two eyes; Interlid crease difference represents the postoperative difference between left and right eyelid show, which is defined as the distance between the upper lid margin and the upper lid fold; interlid show difference represents the postoperative difference in the gap between the upper and lower palpebral rim between the eyes $(8,9)$.

Criteria for evaluation of outcomes included 3-year postoperative follow-up of previously mentioned measurements and assessment of final symmetry.

The operation was considered as a complete success when the following criteria were met at the same time: uMRD between 3 and $5 \mathrm{~mm}$; interlid MRD difference $\leq 1 \mathrm{~mm}$; interlid crease difference $\leq 2 \mathrm{~mm}$ and interlid show difference $\leq 2 \mathrm{~mm}$. If one of these criteria was not completely met but secondary surgery was not necessary, the operation was considered a partial success; if further surgical correction was required, the operation was considered to be a failure
$(5,10)$. Patients were examined at 1 day, 1 week, and 1, 3, 6, 12, 24 and 36 months postoperatively, and postoperative measurements at the last follow-up visit were used for evaluation.

Surgical procedure. Through an anterior approach the upper levator muscle complex was separated from the upper border of the tarsus. Once isolated, the aponeurosis was shortened according to desired eyelid position (2, 3 or $4 \mathrm{~mm}$ of resection for each $\mathrm{mm}$ of desired elevation) and then re-fixed to the upper margin of the tarsus.

Statistical analysis. The descriptive statistical analysis of the results was performed using scatterplot graphics which described the possible relation between age, degree of ptosis, concomitant associated blepharoplasty and the average of collected data: UMRD, interlid uMRD, interlid crease difference, interlid show difference.

\section{Results}

Out of 20 patients enrolled in the study, eight were males and 12 were females (40 eyes). The age range was 18-78 years, with a median of 56 years. Ten patients showed severe symmetric ptosis, two had moderate symmetric ptosis. Patients with asymmetric ptosis showed both severe and moderate degrees of ptosis. Some cases are shown in Figures 3, 4 and 5.

The 3-years postoperative follow-up showed $17(85 \%)$ cases of success and three cases (15\%) of partial success. Overall, 37 eyes $(92.5 \%)$ had an uMRD ranging between $3.12 \mathrm{~mm}$ and $4.87 \mathrm{~mm}$. Two eyes showed hypocorrection: the left eye of case 1 ( $u M R D=2.62 \mathrm{~mm}$ ) and the right eye of 


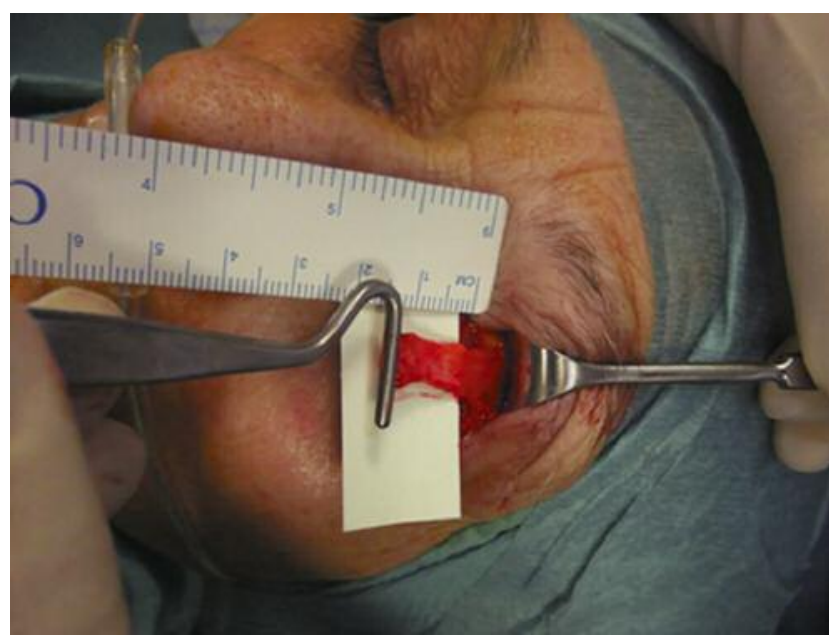

Figure 1. Intra-operative view of the levator muscle complex and its aponeurosis.

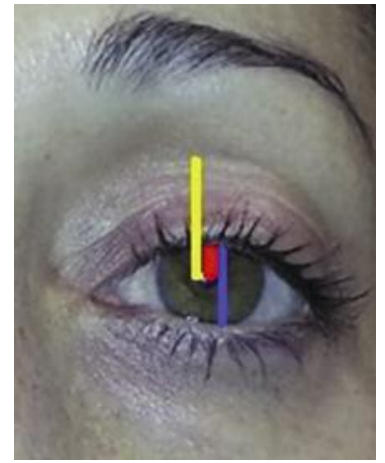

Figure 2. The upper margin reflex index (red line), namely the distance from the central corneal light reflection to the upper lid margin. The lid show (yellow line), defined as the distance between the upper lid margin and the upper lid fold. Palpebral aperture (blue line), defined as the distance between the upper and lower eyelid.

case $8(\mathrm{uMRD}=2.06 \mathrm{~mm})$. The left eye of case 7 was overcorrected ( $\mathrm{UMRD}=5.13 \mathrm{~mm}$ ). Based on criteria selected to evaluate the symmetry, only case 8 was found to be postoperatively asymmetric (interlid uMRD difference of $1.90 \mathrm{~mm}$ and interlid crease difference of $2.33 \mathrm{~mm}$, while interlid show difference was $0.35 \mathrm{~mm}$ ) (Table I).

Among the complications we observed mild lagophthalmos, dry eyes and poor blink in the early postoperative period, which improved several weeks after surgery.

\section{Discussion}

Aponeurotic acquired ptosis is an involutional dehiscence, stretching or thinning of the aponeurotic fibers of the levator aponeurosis from the anterior tarsal surface resulting in a
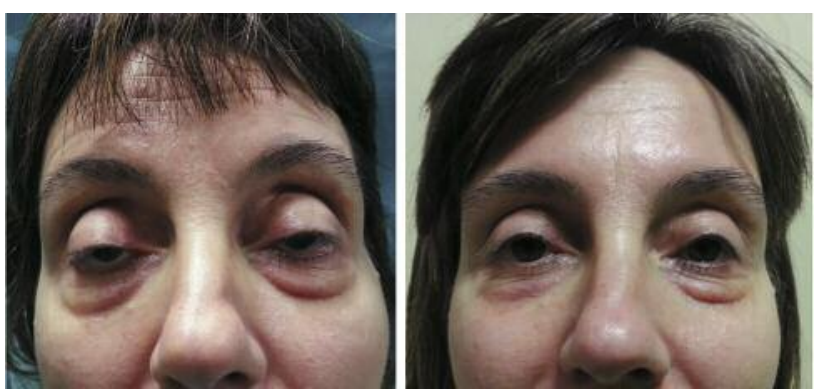

Figure 3. Female patient aged 55 years with symmetric severe ptosis before (left) and after (right) surgery.
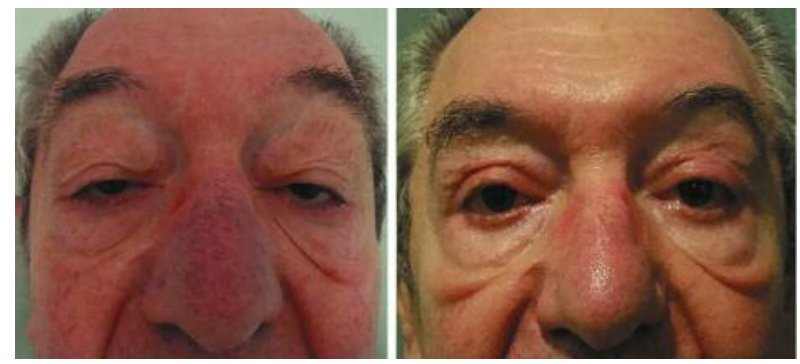

Figure 4. Male patient aged 61 years with symmetric severe ptosis before (left) and after (right) surgery.
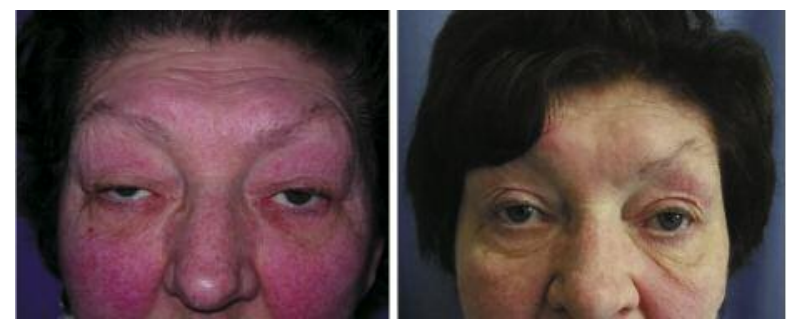

Figure 5. Female patient aged 78 years with asymmetric severe ptosis before (left) and after (right) surgery.

lower upper eyelid position with relative obstruction of the superior visual field. Clinically, it appears with a lower resting upper eyelid position, a superior migration of the upper eyelid crease, a narrowing or loss of the vertical palpebral fissure and normal levator muscle excursion. A compensation for the superior visual field loss by the recruitment of the frontalis muscle is often present. In the case of unilateral ptosis, contralateral eyelid retraction can be observed. Surgical repair is usually required to correct these abnormalities. We report our experience with shortening the levator aponeurosis by an anterior approach 

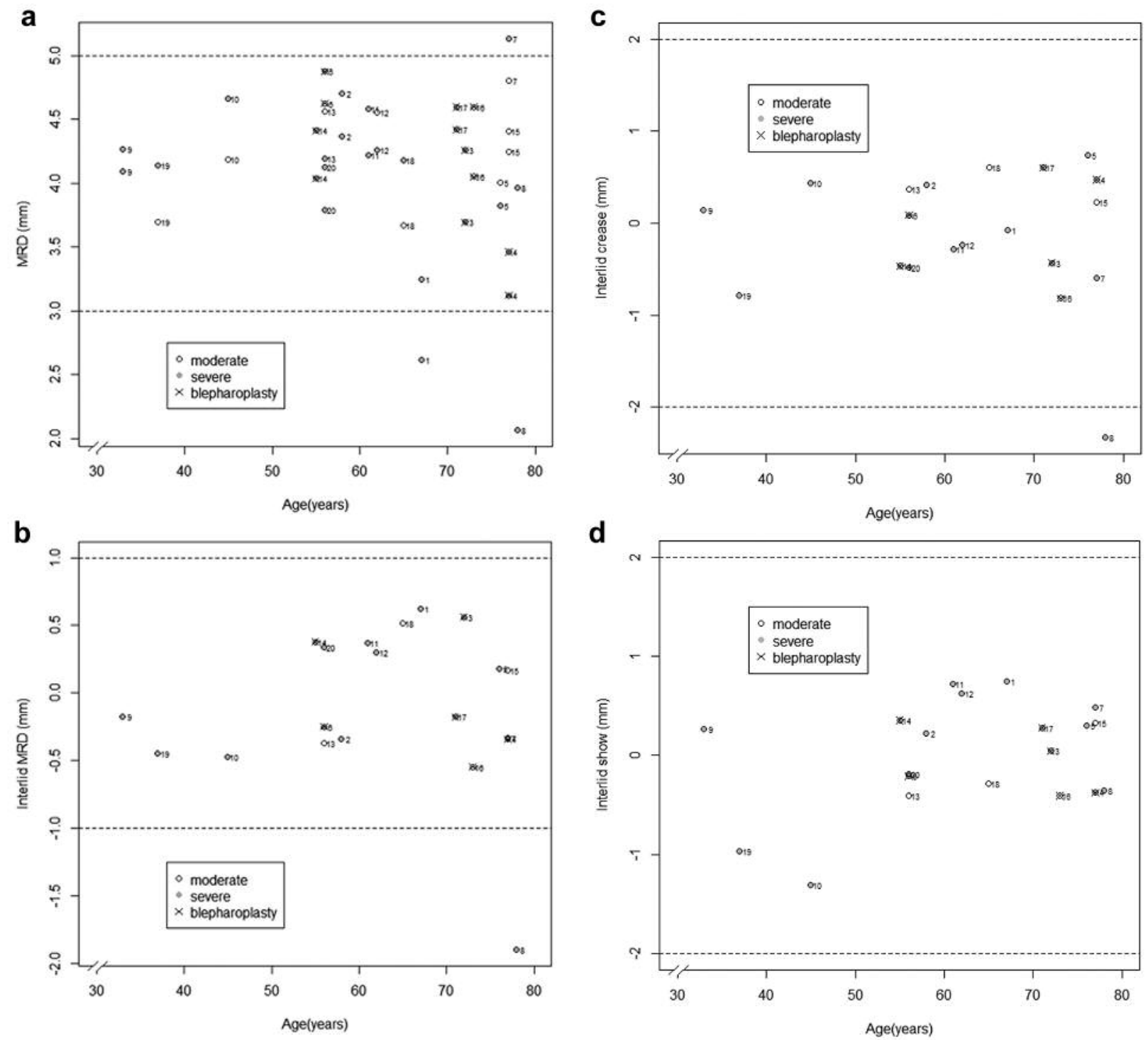

Figure 6. Scatterplot showing upper margin reflex distance $(u M R D)(a)$, and interlid uMRD difference $(b)$, interlid crease difference (c), and interlid show difference (d) between left and right eyes at 3-year follow-up.

through an eyelid crease incision with or without concomitant blepharoplasty (9).

uMRD seems to be the most involved parameter in longterm partial satisfactory results. This probably depends on a decrease of tensile strength of levator aponeurosis during long-term follow-up. At the 3-year postoperative evaluation, 37 eyes $(92.5 \%)$ preserved an UMRD of between 3.12 and $4.87 \mathrm{~mm}$ with most being between 3.5 and $4.5 \mathrm{~mm}$, while three eyes $(7.5 \%)$ did not retain MRD in the correct range. In particular, uMRD of the left eye of case 1 was $3.48 \mathrm{~mm}$ at 1 year postoperatively and $2.62 \mathrm{~mm}$ at 3 years postoperatively, showing a decrease of $0.86 \mathrm{~mm}$ thus resulting in hypocorrection of $0.38 \mathrm{~mm}$ from the correct range. UMRD of the right eye of case 8 was $3.24 \mathrm{~mm}$ at 1 year postoperatively, $2.06 \mathrm{~mm}$ at 3 years postoperatively (reduction of $1.18 \mathrm{~mm}$ ) and was hypocorrected by $0.94 \mathrm{~mm}$. Even if outside the ideal range, the uMRD of both case 1 and 8 were very close to the normal range, diverting from it by less than $1 \mathrm{~mm}$. Although loss of tensile strength of levator aponeurosis was observed at 3 years postoperatively, the difference was not clinically relevant and the symmetric appearance was still globally preserved.

All uMRD outside the ideal range (Figure 6a) was for older patients ( $>67$ years) with a severe grade of ptosis. This 
may suggest that in older patients affected by severe ptosis, hypercorrection may be useful in maintaining more stable long-term results. Furthermore, cases 1, 7 and 8 did not undergo concomitant blepharoplasty. Blepharoplasty may be useful to stabilize the correction.

The interlid MRD and interlid crease of 39 eyes were inside the ideal range (Figure $6 \mathrm{~b}$ and $\mathrm{c}$ ). Only that for the oldest patient (case 8, 78 years old), classified as having asymmetric severe ptosis, was outside the ideal value for both these variables, resulting in asymmetry: the UMRD of her left eye was $2.06 \mathrm{~mm}$ with an interlid uMRD of $1.90 \mathrm{~mm}$ and interlid crease of $2.33 \mathrm{~mm}$. This may depend on the innervation of the levator muscle complex. Since both levator muscles are innervated from a single midline nucleus producing equal neural output to both sides, the less-affected eyelid may be capable of maintaining a normal level of elevation due to excessive nerve stimulation determined by the more ptotic eyelid (Hering's law) (11). Basing on Herring's anatomy considerations, the unsatisfactory final UMRD results observed in case 7 and 8 may be the result of incorrect preoperative assessment. Finally, Figure $6 \mathrm{c}$ and $\mathrm{d}$ seem to show less interlid difference in the patients who underwent concomitant blepharoplasty, which seems to reduce asymmetry, with long-lasting results. External elevator resection enables intraoperative adjustment of the eyelid position. Patient cooperation is strictly necessary to perform ptosis correction adequately and local anesthesia was useful and comfortablely achieved this aim (12).

Limitations of the current study lie in its retrospective design. Although our study included a restricted number of cases, to our knowledge there are no other studies based on such long-term follow-up for correction of aponeurotic ptosis.

\section{Conclusion}

In accordance with a recent study (13), external superior levator advancement for blepharoptosis is an effective procedure in establishing good long-term eyelid position and symmetry,with reported success rates of $85 \%$. Despite the limitations of our study, we believe that external levator advancement is effective in long-term correction of severe aponeurotic ptosis.

\section{References}

1 Collin JRO: Ptosis. Manual of systematic eyelid surgery. Oxford, England: Butterworth - Heinemann; 41-72, 1999.

2 Lee V, Konrad H, Bunce C, Nelson C and Collin JRO: Aetiology and surgical treatment of childhood blepharoptosis. $\mathrm{Br} \mathrm{J}$ Ophtalmol 86: 1282-1286, 2002.

3 Finsterer J: Ptosis: causes, presentation, and management. Aesthetic Plast Surg 27(3): 193-204, 2003.

4 Davies RP: Surgical options for eyelid problems. Aust Fam Physician 31: 239-245, 2002.

5 Scoppettuolo E, Chadha V, Bunce C, Olver JM and Wright M: British Oculoplastic Surgery Society (BOPSS) National Ptosis Survey. Br J Ophtalmol 92: 1134-1138, 2008.

6 Dresner SC: Ptosis management: A practical approach. Peds "Oculoplastysurgery: The essentials", Thieme Medical Publishers, 2001.

7 Feibel RM, Custer PL and Gordon MO: Post cataract ptosis- a randomized double-masked comparison of peribulbar and retrobulbar anesthesia. Ophtalmology 100: 660-665, 1993.

8 Lee S and Schwarcz RM: External levator advancement vs. Muller's muscle-conjunctival resection for correction of upper involutional ptosis. Am J Ophthalmol 140: 426-432, 2005.

9 Innocenti A, Mori F, Melita D, Dreassi E and Innocenti M: Effects of orbicularis oculi flap anchorage to the periosteum of the upper orbital rim on the lower eyelid position after transcutaneous blepharoplasty. Statistical analysis of clinical outcome. J Plast Reconstr Aesthet Surg, 2016. doi: 10.1016/j.bjps.2016.10.019.

10 McCulley TJ, Kersten RC and Kulwin Dr.: Outcome and influencing factors of external levator palpebrae superior's aponeurosis advancement for blepharoptosis. Ophthal Plast Reconstr Surg 19: 388-93, 2003.

11 Gay AJ, Salmon ML and Windsor CE: Hering's law, the levators, and their relationship in disease states. Arch Ophthalmol 77: 157-160, 1967.

12 Linberg JV, VAsquez RJ and Chao GM: Aponeurotic ptosis repair under local anesthesia. Ophtalmology 95: 1046-1052, 1988.

13 Elbakary MA: Posterior approach levator aponeurosis advancement in aponeurotic ptosis repair. Delta J Ophthalmol 16: 32-36, 2015.
Received October 31, 2016

Revised November 25, 2016

Accepted November 29, 2016 